Engineering and Computational Mechanics Volume 165 Issue EM4

\section{Corrigendum}

Dimitrova, Pol, Webb and Fernando

\title{
Corrigendum: Simulations of double-diffusive convection in narrow containers
}

\section{Reneta Dimitrova}

Research Assistant Professor, Environmental Fluid Dynamics Laboratories, Department of Civil Engineering and Geological Sciences, University of Notre Dame, Notre Dame, Indiana, USA

\section{Suhas Pol}

Post-Doctoral Research Associate, Los Alamos National Laboratory, Los Alamos, New Mexico, USA

\section{Stephen Webb}

Distinguished Member of Technical Staff, Geoscience and Environmental Center, Sandia National Laboratories, Albuquerque, New Mexico, USA

\section{larindra J. S. Fernando}

Wayne and Diana Murdy Professor, Civil Engineering and Geological Sciences, University of Notre Dame, Notre Dame, Indiana, USA
The authors regret that the following errors appeared in this paper when it was published in Proceedings of the Institution of Civil Engineers -

Engineering and Computational Mechanics 165(2): 131-145.

In section 2 on p. 132, in the sentence 'In the experiment described here, the inner cylinder was filled with salt stratified water at room temperature $\left(25^{\circ} \mathrm{C}\right)$ with a buoyancy frequency of $N \sim 0.44 / s^{\prime}$, the buoyancy frequency should be $N \sim 0.66 / \mathrm{s}$
In section 3.3 on p. $135, N \sim 0.44 / \mathrm{s}$ should read $N \sim 0.66 / \mathrm{s}$.

Throughout the paper, the units for salinity should be ppm, not $g / l$.

Table 2, presented on p. 139, is incorrect and is a repeat of Table 1. The correct Table 2 is published here.

\begin{tabular}{|c|c|c|c|c|c|}
\hline \multicolumn{6}{|c|}{ Salinity } \\
\hline & MFE: \% & MFB: \% & MAE: ppm & RMSE: ppm & IA \\
\hline Rough & 8.63 & -0.63 & 0.81 & 1.00 & 0.992 \\
\hline Coarse & $14 \cdot 14$ & $4 \cdot 35$ & 0.83 & 1.05 & 0.991 \\
\hline Fine & $6 \cdot 72$ & -0.58 & 0.47 & 0.74 & 0.996 \\
\hline Best & $6 \cdot 87$ & -0.78 & 0.48 & 0.76 & 0.996 \\
\hline \multicolumn{6}{|c|}{ Temperature } \\
\hline & MFE: \% & MFB: \% & MAE: ${ }^{\circ} \mathrm{C}$ & RMSE: ${ }^{\circ} \mathrm{C}$ & IA \\
\hline Rough & $9 \cdot 40$ & $9 \cdot 39$ & $3 \cdot 24$ & $3 \cdot 64$ & 0.993 \\
\hline Coarse & $10 \cdot 20$ & $10 \cdot 20$ & $3 \cdot 46$ & $4 \cdot 16$ & 0.991 \\
\hline Fine & $7 \cdot 88$ & $7 \cdot 88$ & $2 \cdot 70$ & $3 \cdot 40$ & 0.994 \\
\hline Best & $7 \cdot 99$ & 7.99 & $2 \cdot 74$ & $3 \cdot 44$ & 0.994 \\
\hline
\end{tabular}

